\title{
Behaviour of One-Way Reinforcement Concrete Cantilever Slabs with Circle Openings
}

\author{
Aws N. Yaseen ${ }^{1, a,{ }^{*}}$ and Ali H. Ali Al-Ahmed ${ }^{1, b}$ \\ ${ }^{1}$ Civil Engineering Department, University of Baghdad, Baghdad, Iraq \\ a aoussalzaedi@gmail.com,
}

\begin{abstract}
Sometimes there is in need to make openings in the slabs, and this greatly effects on the strength of the structural element. Therefore, this research studies the behaviour of one-way reinforcement concrete cantilever slabs and the extent of their effect and resistance. The number of openings, their location and sizes are the main parameters that have been studied. A comparison was made between four slabs with openings and a fifth reference model (solid slab). After conducting laboratory tests, differences were found in their behaviour and resistance. The decrease in the ultimate load reached $31.5 \%$, while the deflection rate was a decrease between $3.2 \%$ and $62.7 \%$. It was also found that the location and number of openings affected the behaviour of the slab.
\end{abstract}

Keywords: Reinforced concrete; one-way slab; cantilever; opening, circle.

\section{Introduction}

Presently, the need has arisen to have openings in the beams and other structural elements such as the slabs to pass the sewage pipes, water supply, internet lines, and other utilities. Sometimes openings are fabricated in the cantilever part of a slab because the architects have already located emergency stairs or elevators. These openings are of different sizes, shapes, and numbers. The openings lead to many problems, including reducing the resistance, increasing the deflection, and a decrease in the stiffness of the constructor. In addition to many cracks around the openings' location, this decrease in the area of reinforcement concrete in the cross-sectional dimension may make the structural member perform in a complex behavior [1-4].

Al-Ahmed [5] prepared an experimental and theoretical study on self-compacting reinforced concrete two-way slabs with a central square opening under uniformly distributed load. He prepared six models, and the proportions of the area of the openings in them are as follows $(0,2.78,6.25$, $11.11,17.37$, and $25 \%$ ). He found that the largest decrease in the uniform load and the cracking load was in the two models in which the percentage of the openings was $(6.25$ and $11.11 \%)$. Also, there was an increase in deflection as the percentage of opening increased up to $11.11 \%$. Theoretically, supported and clamped edges supported slabs with openings were examined. It was found that with simple supports and a percentage of openings ranging from $(0 \%-25 \%)$, the ultimate uniform load decreases, but after this percentage, the ultimate uniform load increases with the increase in openings ratio. While, for clamped end slabs, the ultimate uniform load and the total ultimate load increase with the increase in the opening ratio. Afefy and Fawzy [6] conducted a study on one-way reinforced concrete slabs with openings, and they found that the openings had a great effect on strength and deflection, as it decreased by half. Al-Hafiz [7] making a study on one-way reinforcement concrete slab with openings strengthened by steel plates. The opening was $19 \%$ of the width of the slab. Different slab thicknesses of $(40,60$, and 80$) \mathrm{mm}$ and different thicknesses of steel plates that were supposed to strengthen the openings were the primary variable of this study. It was found that the thickness of steel plat has played a very important role in increasing the strength. The strength ratio in the slab with the largest thickness has decreased from (3.8-3.4\%) from its original value in the slab that does not contain openings. While the rate of decrease in strength in the remaining slab reached $(23-25 \%)$ of the original percentage.

Casadi [8] tested six models, all of them with one-way reinforcement concrete slab, and they were divided into two groups according to the location of openings, 3 in the middle of the slab and the others near the support. All models were strengthened with CFRP, where the researcher found that this method is successful only when the openings are in the positive moment region when was the 
negative moment region; there was a big problem where a sudden shear failure developed in this region led to a sudden adverse result. The presence of such openings requires taking special measures because it generally leads to a decrease in the bearing; studies and research are somewhat few when it comes to the cantilever slab. This research focuses on studying the effect of the opening in the reinforcement concrete cantilever slab in terms of location and number.

\section{Experimental Program}

There were five models, and the dimensions were as follows: $140 \mathrm{~mm}$ thickness, $600 \mathrm{~mm}$ width, and $2100 \mathrm{~mm}$ length. It was divided into two groups. Each group contains two models, and there is one model as a reference without openings and main steel-reinforced measuring $10 \mathrm{~mm}$ and a second steel-reinforced was $6 \mathrm{~mm}$. The groups were divided according to the number of openings, as the group (A) contained two models with one opening for each model, and the first model differed from the second location of the opening, as in the first model was $200 \mathrm{~mm}$ from the roller support, while was the second $400 \mathrm{~mm}$ from the roller support, and the diameter of one opening was $280 \mathrm{~mm}$. Group (B) contains two models as well, and each model contains two openings. The openings in the first model are $200 \mathrm{~mm}$ from the roller support, the second is $400 \mathrm{~mm}$ from the support, and the diameter of one opening is $200 \mathrm{~mm}$ see Table 1. All material tests and the experimental program were carried out at the University of Baghdad -Civil Engineering Department Laboratory. Note: The area of one opening (diameter $280 \mathrm{~mm}$ ) is equal to the total area of the two openings (diameter $200 \mathrm{~mm}$ ).

Table 1. layout of the typical tested slab.

\begin{tabular}{|c|c|c|}
\hline Slab code & Slabs shape & Opening diameter \\
\hline SS & & N.A \\
\hline SCO-200 & & $280 \mathrm{~mm}$ \\
\hline SCO-400 & & $280 \mathrm{~mm}$ \\
\hline SDCO-200 & & $200 \mathrm{~mm}$ \\
\hline SDCO-400 & & $200 \mathrm{~mm}$ \\
\hline
\end{tabular}

\section{Material Properties}

Concrete. The ready-mix concrete was used by a mixture truck to ensure that all forms were cast under the same conditions. $27 \mathrm{MPa}$, it's the crushing strength of the cube that the mixing of concrete was designed for it after 28 days.

Steel bars reinforcement. Two types of a diameter of steel reinforcement were used, the main 10 $\mathrm{mm}$ and the secondary $6 \mathrm{~mm}$, and the yield stress for them was $610 \mathrm{MPa}$ and $515 \mathrm{MPa}$, respectively

\section{Test Setup and Procedure}

A steel frame was used to support the models. One end is free, the other end is fixed, and support is made at a distance of $850 \mathrm{~mm}$ from the free end as shown in Figure 1. It was of the type of roller. The load was placed as a line load on the free end with load cell have $500 \mathrm{kN}$ maximum capacity, and all this was placed at a distance of $100 \mathrm{~mm}$ from the free end. LVDT was placed under the free end to measuring the maximum deflection. The reinforcement details of tested specimens are shown in Figure 2. 


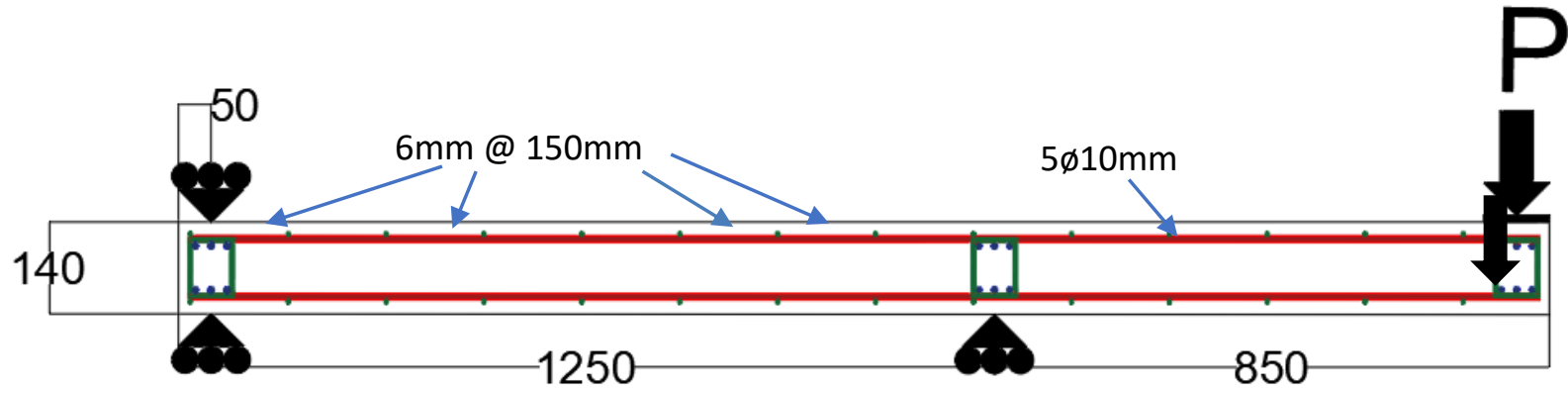

Figure 1. Explains the attitude loading, supported, and side reinforcement details.

(a) slab (SS)

$10 \mathrm{~mm}$

$10 \mathrm{~mm}$

$6 \mathrm{~mm}$

$6 \mathrm{~mm}$

(b) Slab (SCO-200)

$10 \mathrm{~mm}$

$10 \mathrm{~mm}$

$6 \mathrm{~mm}$

$6 \mathrm{~mm}$

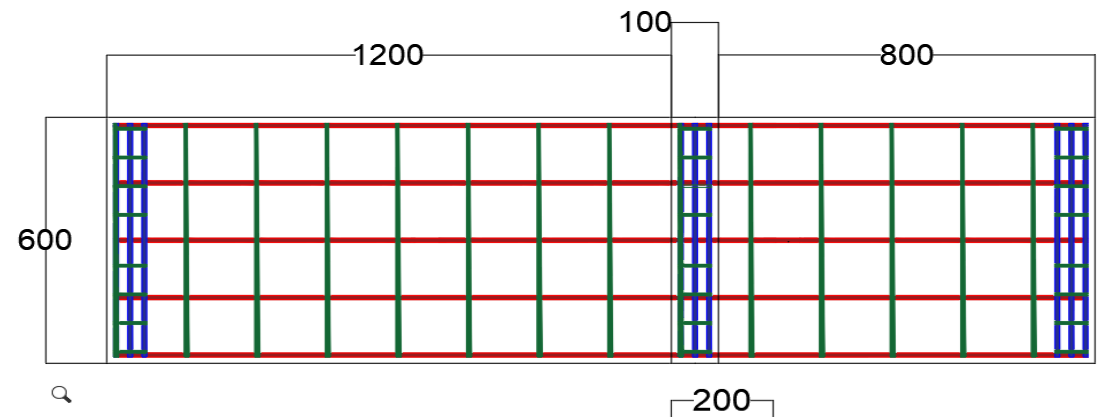

$$
\text { o }
$$

$-200$

$\varnothing 280$

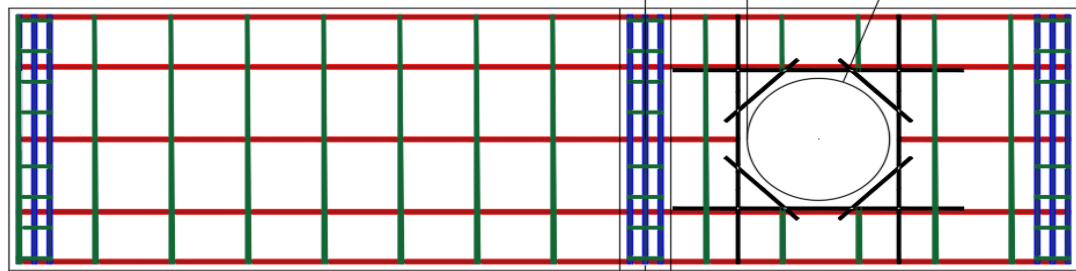

(c) Slab (SCO-400)

$10 \mathrm{~mm}$

$10 \mathrm{~mm}$

$6 \mathrm{~mm}$

$6 \mathrm{~mm}$

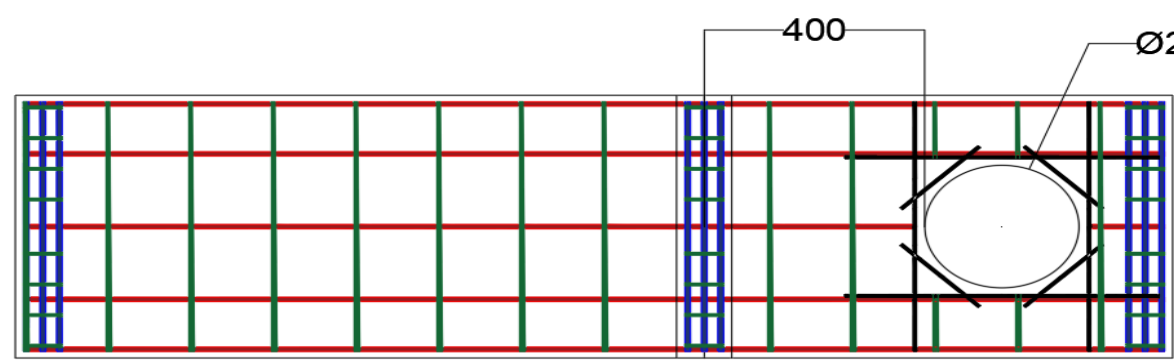

(d) Slab (SCDO200)

$10 \mathrm{~mm}$

$10 \mathrm{~mm}$

$6 \mathrm{~mm}$

$6 \mathrm{~mm}$

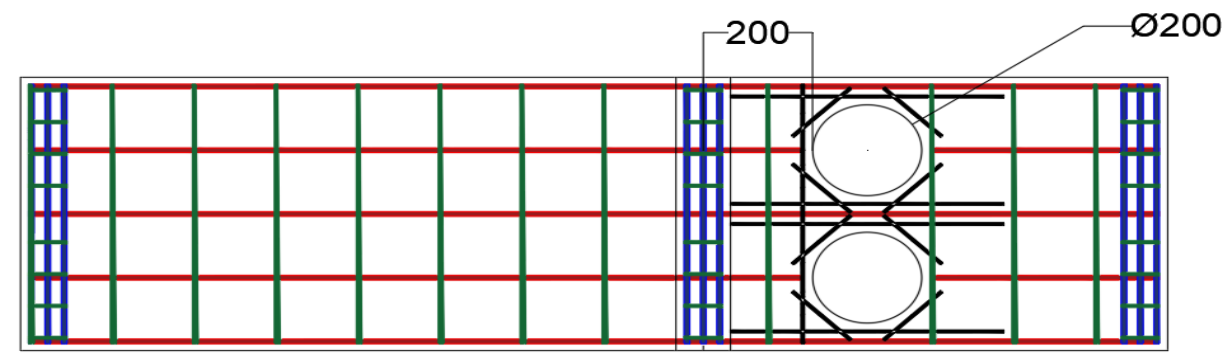

(e) Slab (SCDO400)

$10 \mathrm{~mm}$

$10 \mathrm{~mm}$

$6 \mathrm{~mm}$

$6 \mathrm{~mm}$

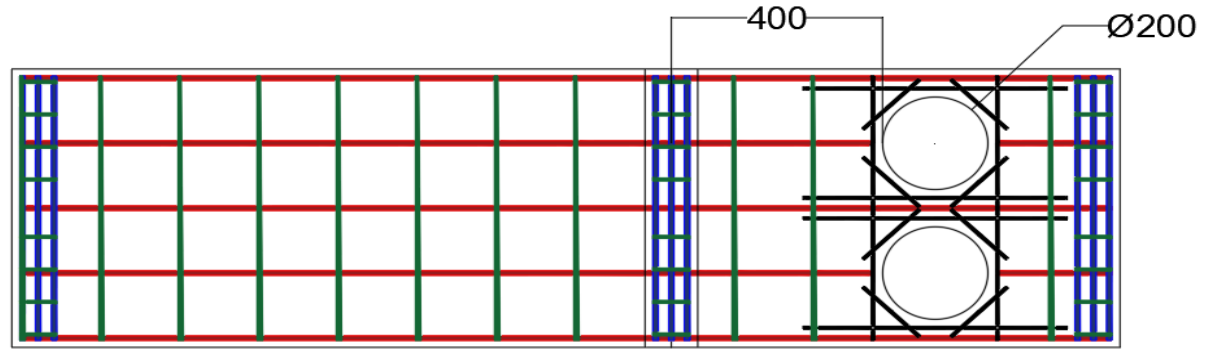

Figure 2. Reinforcement details of tested slabs. 


\section{Test Result and Discussion}

Based on the results presented in Table 2, the SCO- 400 model is the most boring in the aperture models and even the closest result of the SS model. After reviewing the diagrams and results, it was found that the number and location of the openings had a very significant effect on the slab, where the slab was close to the support, the faster the failure and the less strength. When comparing the SCO-200 to the SCO-400 model, they contained one opening each, but the difference between them in the opening position, where it was found that the model SCO-200 shown less resistance than the model SCO-400 due to the location where the model SCO-200 was the closest to the roller support

The SDCO- 400 and SDCO- 200 models, find that the SDCO- 400 model is most bearing to be far from the roller support. When comparing the two models SCO-200 and SDCO-200, in which the openings are in the same location where each of them has openings in it $200 \mathrm{~mm}$ away from the roller support, but they differ in the number of openings, it was found that the model SCO-200 was the strongest of a universe that contains one opening and so on. For the models SCO-200 and SDCO400 , where we observe that the number of openings affects here. The higher the number, the lower the resistance. The crack patterns of tested soil samples are shown in Figure 3 to 7.

Table 2. Results of tested specimens.

\begin{tabular}{|c|c|c|c|c|}
\hline Slabs code & Slabs shape & $\begin{array}{c}\text { Ultimate load, } \\
\mathrm{kN}\end{array}$ & $\begin{array}{c}\text { First crack, } \\
\mathrm{kN}\end{array}$ & $\begin{array}{c}\text { Deflection at } \\
\text { ultimate load, } \mathrm{mm}\end{array}$ \\
\hline SS & & 39 & 7.5 & 94 \\
\hline SCO-200 & D & 35.5 & 6 & 83 \\
\hline SCO-400 & D & 39 & 6 & 91 \\
\hline SDCO-200 & 0 & 26.7 & 6 & 35 \\
\hline SDCO-400 & 0 & 33.8 & 6 & 38 \\
\hline
\end{tabular}
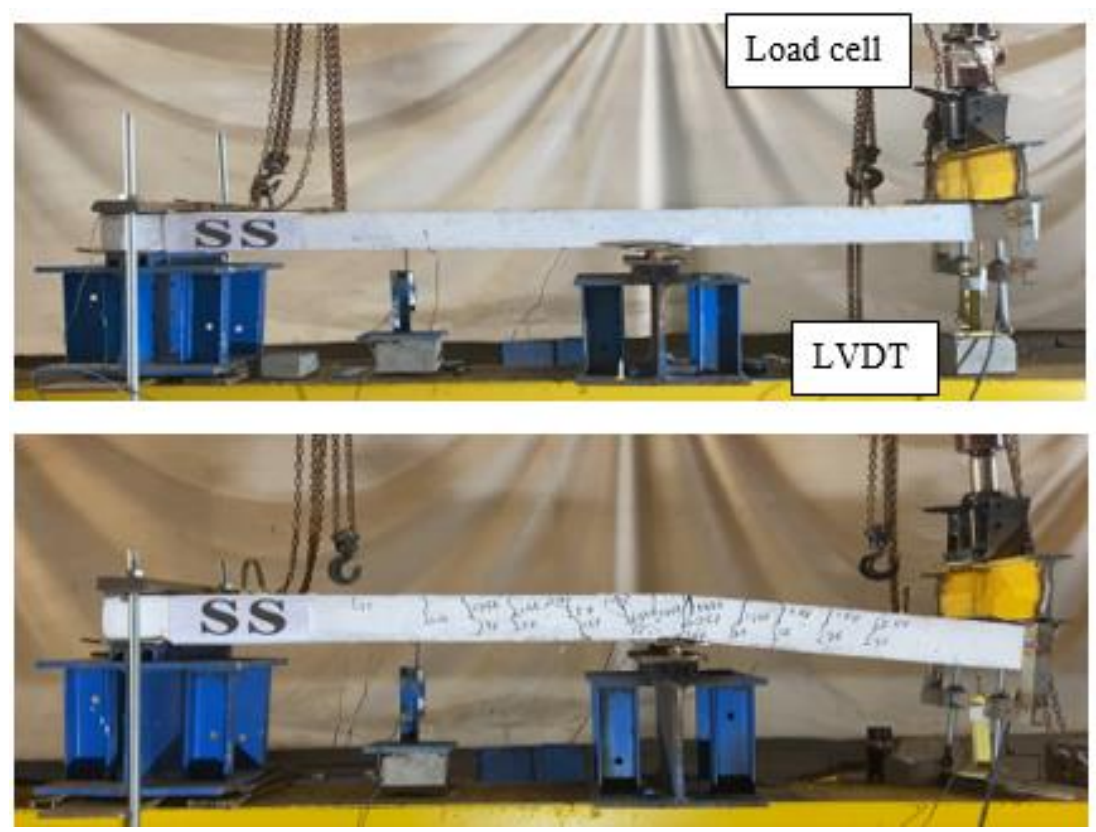

Figure 3. Cracks of SS slab. 
(a) SCO-200 Slab Side view

(b) SCO-200 Slab Top view

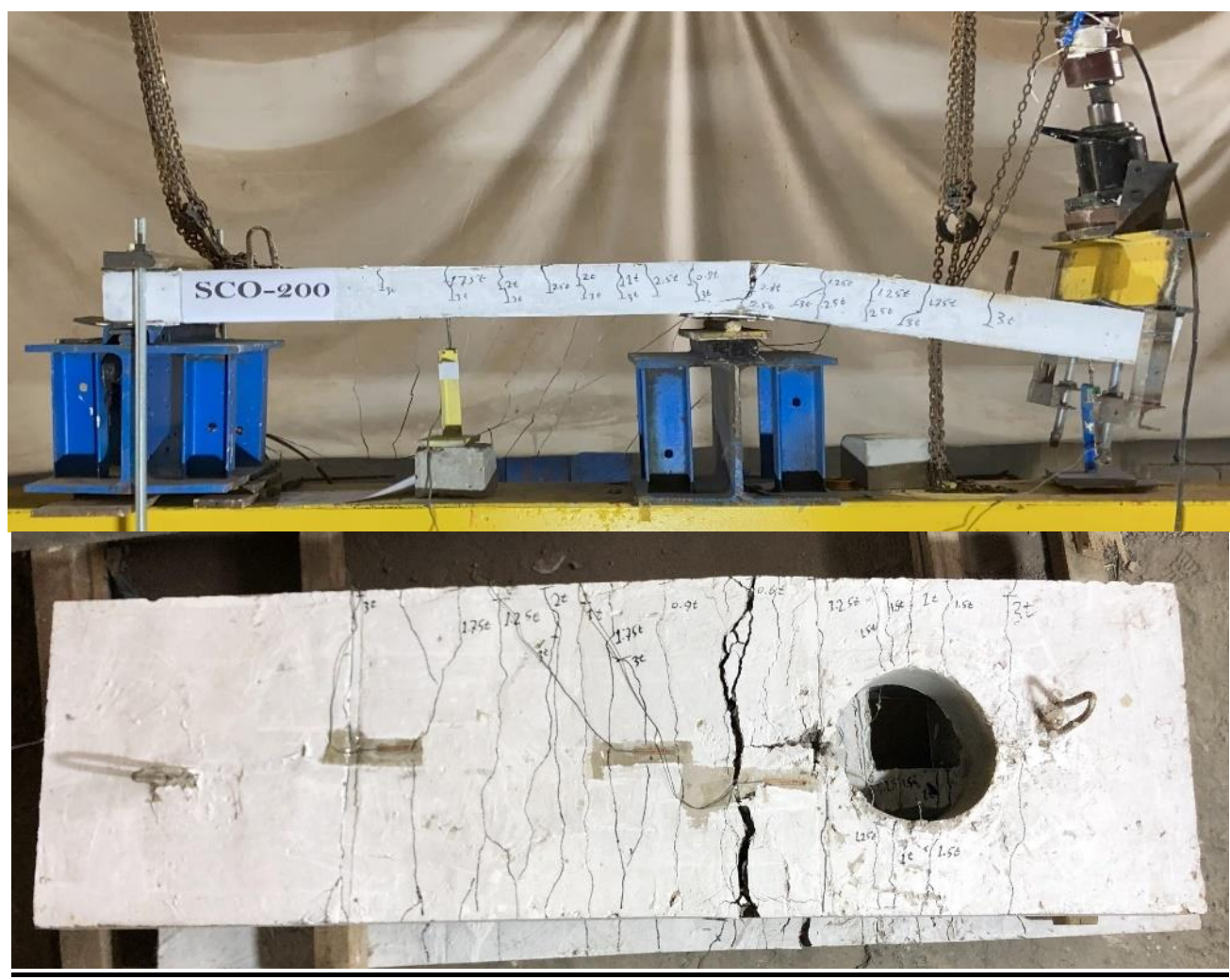

Figure 4. Cracks of SCO-200 slab.

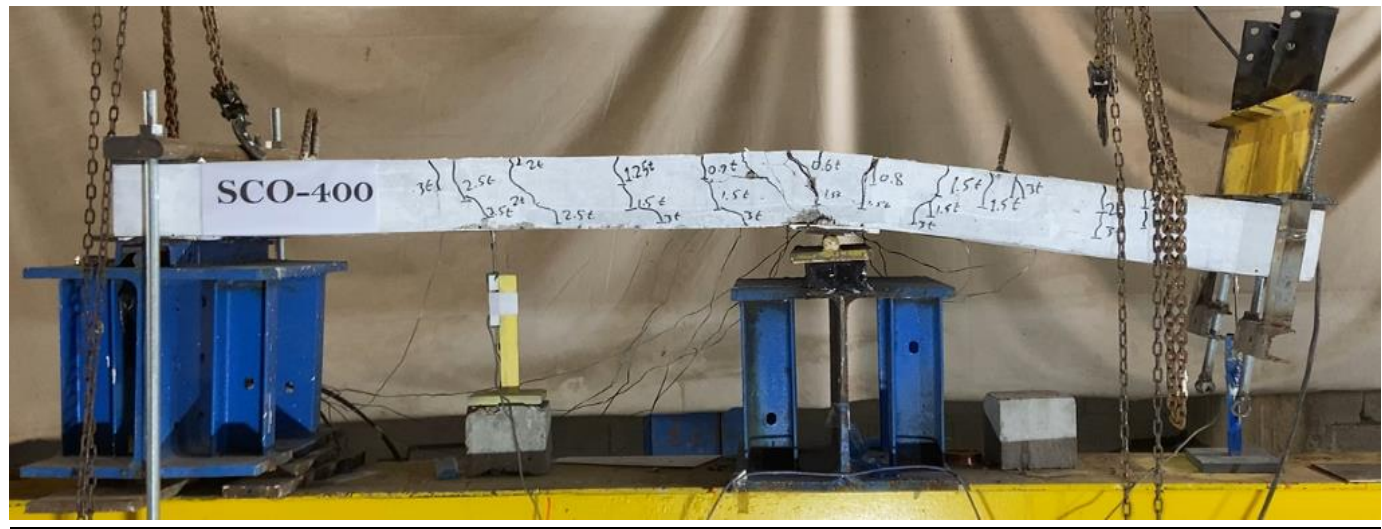

(a) $\mathrm{SCO}-400$

Slab

Side view

(b) SCO-400

Slab

Top view

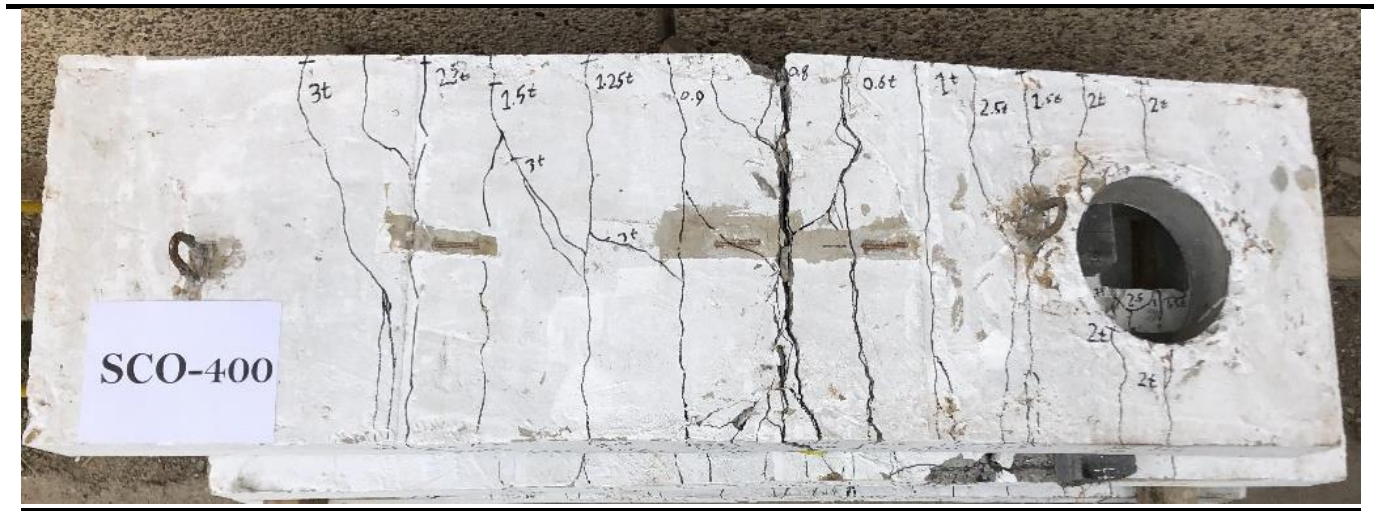

Figure 5. Cracks of SCO-400 slab. 
(a) SDCO200 Slab Side view

(b) SDCO200 Slab Top view

(a) SDCO-400 Slab

Side view

(b) SDCO-400 Slab

Top view

(c) SDCO-400 Slab

Cracks of openings

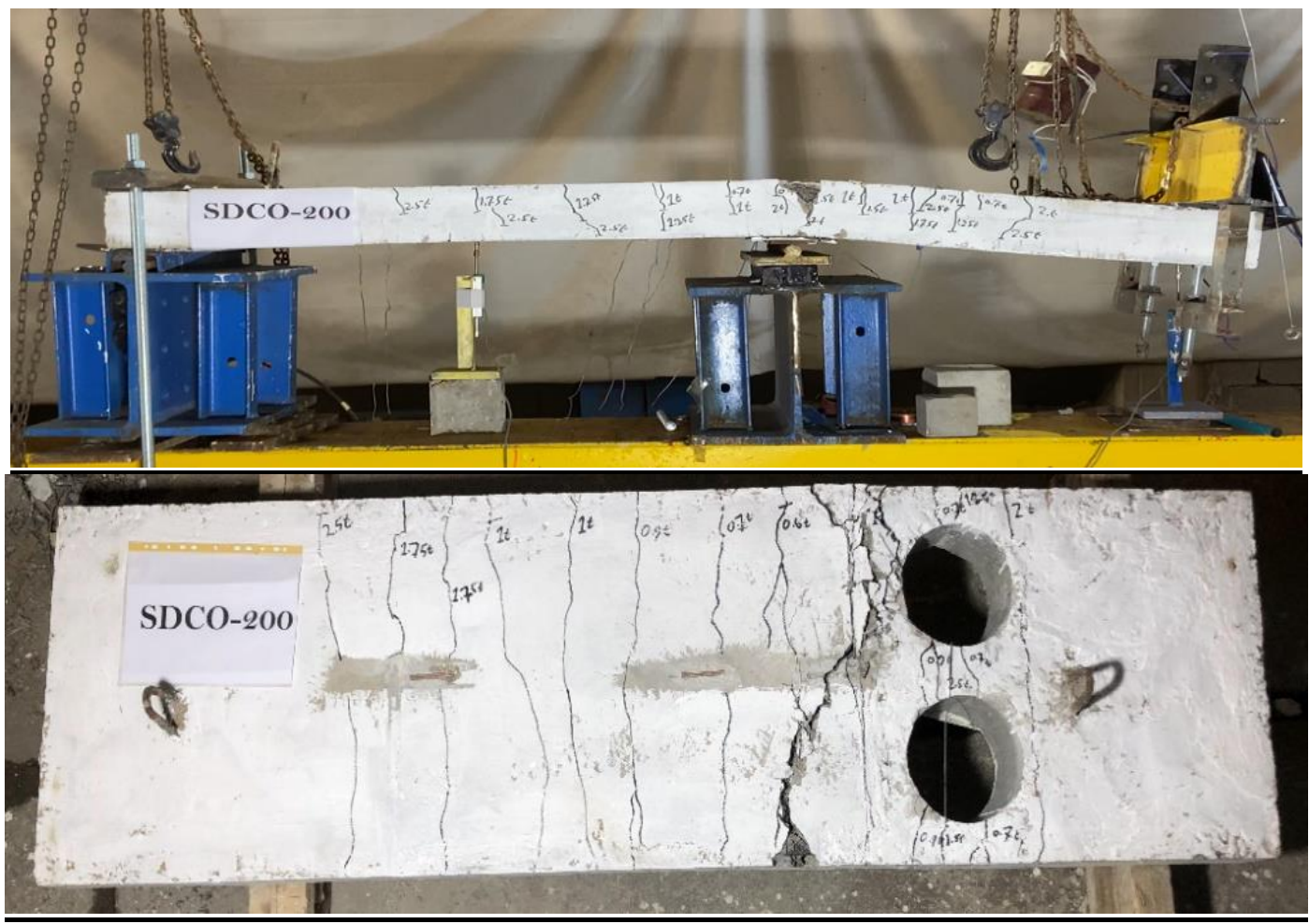

Figure 6. Cracks of SDCO-200 slab.

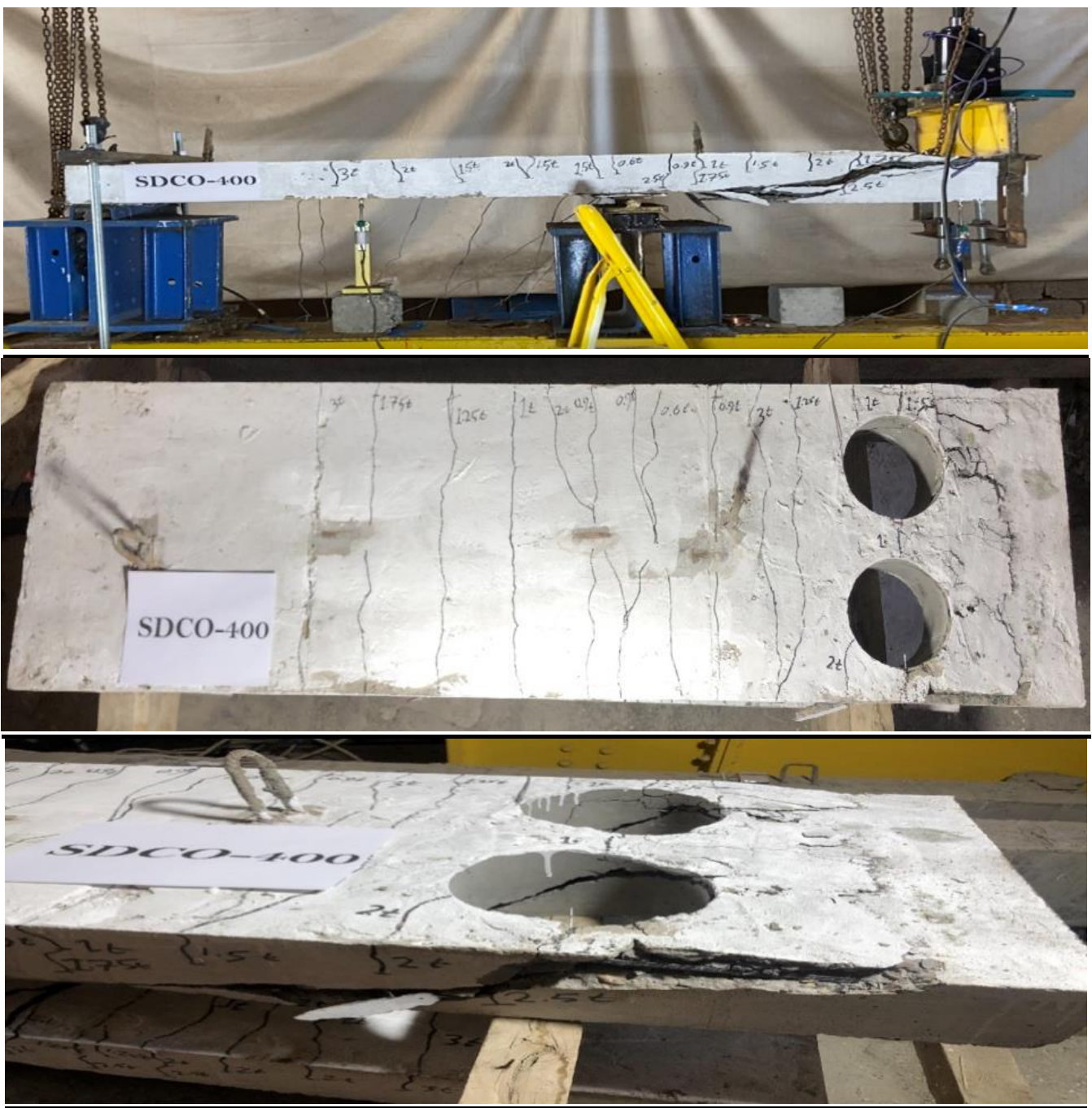

Figure 7. Cracks of SDCO-400 slab. 
Load deflection. By observing Figure 8, it was found that the model (SCO-400) failed with the same ultimate load as the model (SS). The deflection decreased by $3.2 \%$, a tiny percentage, and this model was the strongest. As for the model (SCO-200) failed with less strength, and the decrease rate was $8.9 \%$, and the deflection decreased by $11.7 \%$ from the reference model. The model (SDCO-400) comes in third place, where it failed with an ultimate load of $(33.8 \mathrm{Kn})$, and the percentage of decrease was recorded by $13.3 \%$ of the reference model. The deflection decreased by a considerable and noticeable amount, as the decrease rate was $59.5 \%$ of the deflection of the model (SS). While the most challenging and fastest model to fail was the model (SDCO-200), with a decrease in maximum strength amounting to $31.5 \%$ of the SS model, while the deflection was the lowest among all models, as it decreased by $62.7 \%$. It was found that the most dangerous case is the nearness of the openings to the roller support with an increase in their number, and the best case is their distance from the support with their small number.

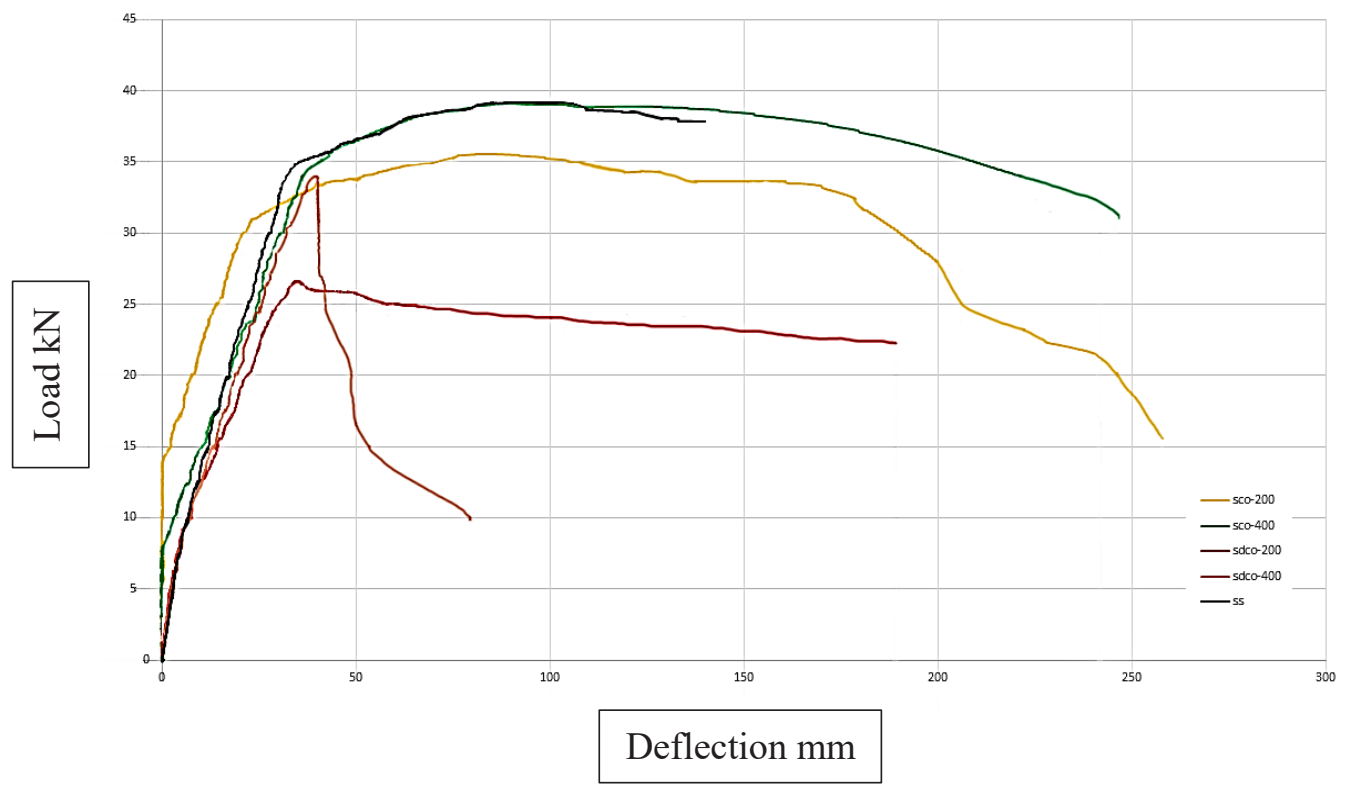

Figure 8. Load-deflection chart.

\section{Conclusions}

- The effect of the number of the openings in the cross-section dimension was very noticeable and by observing the two models SCO-200 and SDCO-200, which were in the location of the same opening and the difference only in the number of openings where the ultimate load was 35.5 and $26.7 \mathrm{kN}$, while the deflection was $83 \mathrm{~mm}$ and $35 \mathrm{~mm}$ respectively. The models SCO400 and SDCO-400, the ultimate load was 39 and $33.8 \mathrm{kN}$ and the deflections were 91 and 38 $\mathrm{mm}$ respectively, so increasing the number of openings has a very negative effect on the structure.

- The location of the openings has a very important role, as the two models SCO-200 and SCO400 , which contain the same number of openings in different locations, where the ultimate load was 35.5 and $39 \mathrm{kN}$, and the deflection was $83 \mathrm{~mm}$ and $91 \mathrm{~mm}$ respectively. In comparison, the two models SDCO-200 and SDCO- 400, the ultimate load was 26.7 and 33.8 $\mathrm{kN}$ and deflection are 35 and $38 \mathrm{~mm}$ respectively, we have found the location of the openings had a very big effect on the ultimate load, more than the deflection and that the most dangerous situation that a structural element could be exposed to from the above is that it contains a large number of openings and be close to the support, which is the case of the SDCO-200 model.

- The SDCO-400 model behaved in a completely different way, as it failed from the opening locations with a sudden shear failure because the distance between the openings is very small and the nearness of the openings to the loading place. 


\section{References}

[1] Chin, S.C., Shafiq, N., Nuruddin, M.F. and Farhan, S.A., 2012. Strengthening of RC beams with large openings in shear by CFRP laminates: Test results. In International Conference on Civil, Offshore and Environmental Engineering.

[2] Mansur, M.A., 2006, September. Design of reinforced concrete beams with web openings. In Proceedings of the 6th Asia-Pacific structural engineering and construction conference (ASPEC 2006) (pp. 5-6). Kuala Lumpur.

[3] Khalil, A.E.A., Atta, A.M., Baraghith, A.T. and Kandil, D.O., ICASGE'19.

[4] Allam, S.M., 2005. Strengthening of RC beams with large openings in the shear zone. Alexandria Engineering Journal, 44(1), pp.59-78.

[5] Al-Ahmed, A.H.A., 2016. Nonlinear behavior of self-compacting reinforced concrete two-way slabs with central square opening under uniformly distributed loads. Journal of Engineering, 22(7), pp.35-54.

[6] Afefy, H.M. and Fawzy, T.M., 2013. Strengthening of RC one-way slabs including cut-out using different techniques. Engineering Structures, 57, pp.23-36.

[7] Al-Hafiz, A.M., Chiad, S.S. and Farhan, M.S., 2013. Flexural strength of reinforced concrete one-way opened slabs with and without strengthening. Australian Journal of Basic and Applied Sciences, 7(6), pp.642-651.

[8] Casadei, P., Ibell, T. and Nanni, A., 2003. Experimental results of one-way slabs with openings strengthened with CFRP laminates. In Fibre-Reinforced Polymer Reinforcement for Concrete Structures: (In 2 Volumes) (pp. 1097-1106). 